\title{
HUELGAS E INTERCAMBIO POLÍTICO EN ESPAÑA
}

\author{
STRIKES AND POLITICAL EXCHANGE IN SPAIN
}

\author{
DAVID LUQUE luquedavid@uniovi.es \\ Universidad de Oviedo. España
}

\begin{abstract}
RESUMEN
A pesar de ser España uno de los países europeos con mayor actividad huelguística durante los últimos treinta años, la investigación empírica en este campo es inusualmente escasa y adolece de la falta de un análisis de largo recorrido. En este trabajo se aborda el estudio de la actividad huelguística en España durante las tres últimas décadas con el principal objetivo de desarrollar una explicación teóricamente fundada de su evolución y de sus principales mecanismos causales. Del análisis desarrollado se desprende que el acusado descenso de los niveles de conflictividad registrados durante los últimos quince años es atribuible al desplazamiento de la lucha por la distribución de la renta del mercado, donde la huelga es el principal mecanismo de presión, al ámbito político, donde las modalidades de actuación no se limitan a la huelga.
\end{abstract}

\section{Palabras Clave}

Concertación social; Conflicto industrial; Intercambio político.

\begin{abstract}
Although Spain has been one of the European countries with greater strike activity during the last thirty years, empirical research in this field is unusually low. In this work, strike activity in Spain is analyzed with the aim of developing an explanation of its evolution and its main causal mechanisms. The analysis shows that the sharp decline in the levels of industrial conflict recorded during the last fifteen years is attributable to a shift in the mode of distribution of the income from the production sphere, where the strike is the main mechanism of pressure, to the political arena where the modes of acting are not limited to the strike.
\end{abstract}

\section{KEYWORDS}

Industrial Conflict; Political Exchange; Social Dialogue. 


\section{INTRODUCCIÓN}

Las huelgas son el aspecto más destacado del conflicto de trabajo yal que la literatura académica ha concedido mayor trascendencia, tanto por su relevancia social —probablemente las huelgas han involucrado más trabajadores que cualquier otra forma de acción colectiva durante el siglo XX - como por su continuidad histórica, ya que desde mediados del siglo XIX las huelgas se convirtieron en la forma dominante de protesta social en las sociedades industriales (Shalev 1989).

Con todo, el descenso cuantitativo de la actividad huelguística en las últimas décadas en la mayoría de los países occidentales ha hecho que las huelgas pierdan gran parte de su relevancia social y también de su atractivo académico. De este modo, después de la última gran oleada de huelgas en Europa occidental a finales de los sesenta y principios de los setenta - que sorprendió a quienes se habían dedicado a estudiar las causas de la paz laboral de los años cincuenta y sesenta-, la producción científica sobre el tema ha decaído sustancialmente y no como consecuencia de haber encontrado todas las explicaciones para un fenómeno tan complejo como las huelgas. Tampoco porque todo haya quedado resuelto, sino más bien porque las huelgas "pasaron de moda" tras un nuevo declive de la actividad huelguística en los ochenta y noventa, y las opciones para obtener fondos para proyectos y becas de investigación se redujeron ante la emergencia de nuevas materias (Franzosi 1995).

No obstante, trabajos como los de Piazza (2005), Scheuer (2006), van der Velden et al. (2007), Perry y Wilson (2008), Bordogna (2010) — por citar algunos de los más recientes- muestran un interés renovado en la materia. No en vano, las huelgas continúan siendo una de las figuras centrales, en muchos casos esencial, de las relaciones laborales. Los medios de comunicación todavía se hacen eco de forma frecuente de huelgas planteadas por el cierre de las instalaciones de una empresa 0 ante los recortes en la plantilla por el desplazamiento de la producción a países con bajos costes laborales, de huelgas en los transportes públicos por la renovación del convenio colectivo, de huelgas por la privatización de servicios públicos, de huelgas por el retraso reiterado 0 la falta de pago de los salarios, etc. La huelga sigue siendo, por tanto, la principal forma de expresión de descontento y de protesta por parte de los trabajadores, y no solo de los de "cuello azul".

En España, a todo lo anterior se suma el hecho de ser, de manera sistemática desde la transición a la democracia, uno de los países europeos con mayor actividad huelguística. Incluso durante el largo periodo de crecimiento económico previo a la actual crisis los registros españoles seguían situándose entre los más altos de Europa (European Industrial Relations Observatory 2005).

Además, el caso español resulta especialmente útil para el estudio de las huelgas debido, entre otros motivos, a su reciente -en términos comparados con los países europeos centrales- (re)institucionalización de las relaciones laborales una vez finalizado el régimen dictatorial. De esta forma, enlazando distintas series es posible analizar 
la evolución a grandes rasgos del conflicto industrial una vez institucionalizado mediante la legalización tanto de las organizaciones sindicales y empresariales como de las huelgas en el año 1977.

El objetivo principal de este trabajo es desarrollar una explicación teóricamente fundada de la evolución de la actividad huelguística y de sus principales mecanismos causales. Para ello el trabajo se estructura de la siguiente forma. Tras este apartado de introducción, se presenta el marco teórico de la investigación del que se derivan las hipótesis de trabajo. A continuación, se describen las principales fuentes de información sobre las huelgas en España. En el cuarto apartado se analiza la actividad huelguística durante el periodo democrático diferenciando para ello cuatro etapas en función de su intensidad. Finalmente, el trabajo concluye con un apartado de conclusiones.

\section{MARCO ANALÍTICO DE LA INVESTIGACIÓN}

En la amplia literatura internacional sobre los determinantes de la actividad huelguística se pueden diferenciar dos corrientes principales: el enfoque económico y el políticoorganizativo. La primera aproximación, predominante en la escasa literatura nacional (Marco, Esteve y Rochina 2007; Jiménez-Martín 2006; Marco y Tamborero 2001; Marco 2000; Jiménez-Martín 1999; Jiménez-Martín, Labeaga y Marco 1996), inserta el problema en el ámbito de los modelos de negociación, concibe la huelga como una decisión racional por parte de los actores implicados en el conflicto, decisión influenciada por la situación del ciclo económico (Ashenfelter y Johnson 1969). La segunda perspectiva considera la huelga como una forma de acción colectiva que no puede reducirse por completo a objeto de cálculo económico, en su origen se privilegian los factores causales políticoorganizativos (Shorter y Tilly 1974).

Esta investigación ha optado por aproximarse al estudio de las huelgas como una forma de acción política que no se debe confundir con la tradicional distinción entre las huelgas económicas y políticas, basada en los objetivos de las reivindicaciones, sino que se basa en la lógica de acción que guía a las huelgas. La otra lógica de acción o enfoque para aproximarse a las huelgas sería la económica, basada en modelos de negociación. Por consiguiente, la óptica político-organizativa será la que oriente el análisis.

\section{La teoría del intercambio político}

El "resurgimiento del conflicto de clase" a finales de la década de los sesenta mostró por la fuerza de los hechos que los argumentos unitaristas - centrados en el interés común entre trabajadores y empleadores, considerando las huelgas como antinaturales e innecesarias, consecuencia de impulsos irracionales ante el proceso de industrialización o resultado de un déficit de integración en el sistema industrial- eran erróneos. En consecuencia, se desarrollaron nuevas argumentaciones para tratar de explicar la 
tendencia a largo plazo de las huelgas. Entre ellas cabe resaltar la denominada como "teoría del intercambio político". Teoría que alcanzó notoriedad en los setenta y que relaciona los niveles de conflictividad en el medio y largo plazo con la orientación ideológica del gobierno y la incorporación del movimiento obrero a la esfera políticagubernamental.

Entre otros autores, Cameron (1984), Korpi y Shalev (1979), Hibbs (1978), Pizzorno (1978) y Shorter y Tilly $(1971 ; 1974)$ señalan que, contrariamente a lo sostenido por la corriente pluralista - según la cual el conflicto se da dentro del proceso de negociación colectiva-, también es importante el uso de los "recursos de poder" en la esfera de la política. De este modo, los partidos socialdemócratas son considerados como uno de los principales "recursos de poder" con los que cuentan los trabajadores para alterar los resultados del mercado a través de la política (Korpi 1983).

Desde esta perspectiva analítica, las huelgas son vistas como "un instrumento de acción colectiva de la clase trabajadora" y, por lo tanto, la actividad huelguística se considera "una manifestación de la lucha en curso por el poder entre clases sociales sobre la distribución de los recursos, principalmente - aunque no de forma exclusiva-la renta nacional" (Hibbs 1978:165). De este modo, las alteraciones en la intensidad de la actividad huelguística a medio y largo plazo pueden ser atribuidas a cambios en la localización de la lucha por la distribución de la esfera de la producción a la esfera de la política.

En esencia, el argumento que plantean estos autores es que el afianzamiento de los partidos de orientación socialdemócrata en algunos gobiernos nacionales - caso paradigmático de Suecia a mediados de la década de los treinta- abrió nuevos ámbitos de acción al movimiento obrero. De esta forma, parte de las reivindicaciones tradicionalmente canalizadas a través de la huelga se integraron en los programas políticos de los partidos socialdemócratas reduciéndose los niveles de conflictividad laboral al alcanzar estos partidos el gobierno. Así, se produce un "intercambio" entre los trabajadores y el Estado, que compensa - 0 al menos, promete compensar-a los trabajadores por los sacrificios que realizan en el mercado de trabajo, ya sea en forma de un salario social más alto o con cambios en el tipo impositivo sobre los ingresos de los trabajadores (Lange 1984). Así, los sindicatos tuvieron acceso a una alternativa política a las huelgas, relativamente eficiente, que pudieron usar para "lograr metas importantes, fundamentalmente a través de cambios en las políticas de empleo, fiscales y sociales" (Korpi 1978:99, citado en Bean 1985:143).

De este modo, en países como Suecia, Noruega y Austria, donde los partidos socialdemócratas habían sido los partidos dominantes en el gobierno, los niveles de conflictividad experimentaron un declive a largo plazo, reflejo de que el conflicto por la distribución de la renta paso del mercado de trabajo a la esfera política. En el extremo opuesto, en países como Irlanda, Estados Unidos y Canadá, donde la clase obrera nunca ha tenido un papel determinante en la política nacional, no se produjo tal declive (Korpi 2002; Korpi y Shalev 1979). Además, es algo más que una coincidencia que, después de la exclusión de los socialdemócratas suecos del gobierno a mediados los setenta, hubiera un resurgimiento del conflicto industrial (Bean 1985). 
Como en toda situación de intercambio, en el intercambio en el ámbito político los actores toman en consideración no solamente su interés inmediato a corto plazo, sino también sus objetivos futuros. De este modo, los sindicatos renuncian a la obtención de mejoras a corto plazo en la esfera de la producción a través del recurso a la huelga, por lograr de forma más efectiva sus intereses a largo plazo en la esfera política.

Para que este proceso de intercambio tenga lugar de forma exitosa son necesarias una serie de condiciones. En primer lugar, la fuerza del "trabajo" dentro del gobierno debe de ser estable y con perspectivas de ser perdurable, "no solo para que los sindicatos se convenzan de los beneficios de una política de menor militancia, sino también para persuadir a los empresarios a alcanzar un alojamiento duradero con ellos" (Bean 1985:143). Asímismo, la experiencia pasada es un elemento importante, en la medida en que se haya llevado a cabo este tipo de intercambio previamente con éxito (Lange 1984). De igual modo, para cumplir con su parte del acuerdo "el movimiento obrero requiere un importante grado de unidad organizacional entre y dentro de sus alas industrial y política junto con control interno y disciplina sobre sus componentes" (Bean 1985:144).

Cuando estas condiciones no se dan, es probable que la relación entre gobiernos de orientación de izquierda y reducción de la conflictividad, de igual modo, tampoco se dé. Incluso puede que el nivel de conflictividad aumente (Paldam y Pedersen 1982).

La teoría del intercambio político incorpora una perspectiva dinámica en el análisis de la actividad huelguística, en el sentido de que contempla que se puedan dar situaciones de desestabilización y conflicto cuando los sindicatos no pueden o no están dispuestos a intercambiar moderación reivindicativa en el corto plazo por poder político (Pizzorno 1978). Esto puede ocurrir, principal pero no únicamente, cuando se produce algún cambio en las posiciones del gobierno desfavorable a las reivindicaciones de los sindicatos y de los trabajadores, impidiéndoles aspirar a beneficios futuros a cambio de moderación en ese momento. En consecuencia, "o los propios sindicatos, o la base, considerarán oportuno adoptar una postura agresiva" (Pizzorno 1978: 401), perdiendo sentido no solo la moderación sino también la acción coordinada.

En comparación con otros esquemas teóricos utilizados en el estudio de las huelgas, el marco general del intercambio político presenta al menos dos ventajas principales. Por un lado, a partir de este esquema se puede derivar la aparición de periodos de desestabilización y conflicto, confiriéndole una perspectiva dinámica al marco analítico. De este modo, es compatible con la evolución discontinua de la actividad huelguística, lo que le otorga una mayor capacidad explicativa que aquellos esquemas teóricos más estáticos centrados en las instituciones. Por otro lado, la consideración de dos vías principales de acción: la política y la contractual o de mercado, supone una ventaja respecto a otros esquemas teóricos que predicen asimismo fluctuaciones en la intensidad de la actividad huelguística, como el modelo de los ciclos económicos, pero cuyo enfoque es más restringido al no considerar la importancia de factores políticos.

Además, este enfoque resulta especialmente útil en el estudio del caso español en la medida en que el marco institucional de las relaciones laborales - en el que el Estado 
ha desarrollado el papel principal en materia de regulación y la naturaleza de clase de los sindicatos mayoritarios y su debilidad organizativa a nivel de empresa- hace de la acción política la estrategia de acción más factible para lograr mejoras o defender conquistas en el mercado de trabajo. La evidencia así lo demuestra, las relaciones laborales en España durante las últimas tres décadas han estado marcadas en buena parte por una pauta discontinua de concertación social: iniciada a finales de los setenta, interrumpida temporalmente a mediados de los ochenta, y que resurge mediados los noventa.

De este modo, el marco analítico que se propone trata de aprovechar la amplia literatura sobre el neocorporatismo, entendido este como un proceso de elaboración de políticas -neocorporatismo 2 en los términos de Schmitter (1982)—, conectándola con la escasa producción nacional sobre huelgas. No en vano, concertación y huelgas son las caras opuestas de las relaciones entre sindicatos, empleadores y Estado. Así, el término "intercambio político" es utilizado tanto en la literatura sobre la concertación (Lehmbruch 1984; Regini 1984; más recientemente: Molina y Rhodes 2002; Molina 2006) como en la de huelgas (Hibbs 1978; Korpi y Shalev 1979; Cameron 1984; Pizzorno 1978). En la primera enfatizando su papel como "un medio para alcanzar el consenso en la formulación de políticas" (Molina y Rhodes 2002:321), en la segunda, como forma de resolver el conflicto básico por la distribución de la renta en la esfera política.

Hay que destacar por último, que en el análisis no solo se tendrán en cuenta los factores contextuales (entorno económico, cambios institucionales, clima político...), esto es, el porqué; sino también, y de forma principal, las decisiones estratégicas de las partes implicadas, es decir, el cómo. Por lo tanto, se adopta un enfoque que enfatiza la importancia de la estrategia de los actores, principalmente uno de ellos: los sindicatos, lo cual implica la posibilidad de adaptación, de una evolución en la naturaleza del "intercambio político" en función de las condiciones internas y de las presiones externas.

\section{Hipótesis de trabajo y pregunta de investigación}

Esta investigación parte de la hipótesis básica de que las huelgas en España responden principalmente a una lógica de acción política más que a una lógica de acción meramente económica y, por lo tanto, en el análisis de su evolución se privilegiarán las relaciones de los actores de las relaciones laborales en el ámbito político.

Así, en lo que respecta a la evolución de las huelgas en España, si realmente las huelgas se aproximan en mayor medida a una lógica de acción política, cabría esperar que las fluctuaciones en la actividad huelguística no viniesen determinadas, al menos principalmente, por el ciclo económico. De este modo, en la medida en que el conflicto básico por la distribución de la renta se desplaza del mercado de trabajo al ámbito político, el poder relativo de negociación de los trabajadores - que depende del grado de ajuste en que se encuentra el mercado de trabajo: la tasa de desempleo- no determinaría la frecuencia de las huelgas. Las mayores inflexiones en la intensidad de la actividad huelguística vendrían determinadas por las distintas fases por las que ha discurrido la 
concertación social durante el periodo democrático. Así, cabría esperar una reducción de la frecuencia de las huelgas en aquellos periodos en los que el diálogo social ha sido fructifero, al desplazar de forma efectiva el conflicto distributivo al ámbito político. Por otra parte, la ruptura de la dinámica de concertación y, por lo tanto, del intercambio político subyacente, se debería reflejar de modo inmediato en el tamaño de las huelgas, que aumentaría notablemente ante la concurrencia de huelgas generales, expresión de rechazo a posturas contrarias a los intereses generales de los trabajadores. Este tipo de huelga refleja un "intercambio político negativo" y suelen ser frecuentes, de igual modo, cuando los intereses de los trabajadores no están representados -o sus representantes están excluidos- del ámbito de decisión política, actuando, así, como forma de presión extraparlamentaria en busca de desarrollos legislativos favorables.

En definitiva, en este trabajo se trata de dar respuesta a la siguiente pregunta: ¿las huelgas en España responden a una lógica de acción política?

\section{Las estadísticas de huelgas en España}

La principal fuente de información disponible a nivel nacional es la Estadística de Huelgas y Cierres Patronales (EHCP) que elabora el Ministerio de Trabajo e Inmigración (MTIN) y que proporciona información, tanto a nivel nacional como autonómico, sobre el número de huelgas, centros afectados, trabajadores convocados, participantes y jornadas no trabajadas.

La EHCP es una estadística de registro administrativo que se publica anualmente de forma ininterrumpida desde 1986. Los promotores de una huelga tienen la obligación legal de comunicar a la autoridad laboral competente la convocatoria de la misma. A partir de esta comunicación la autoridad laboral realiza el seguimiento de la huelga. Este seguimiento se realiza principalmente a nivel regional y mensualmente se cumplimenta un cuestionario sobre las huelgas acontecidas durante el mes, que se remite posteriormente a la Subdirección General de Estadísticas del MTIN encargada de elaborar con periodicidad anual la EHCP.

Para el periodo previo a 1986 se ha recurrido al Anuario de Estadísticas del Trabajo elaborado por la Organización Internacional del Trabajo (OIT), tras contrastar con las fuentes nacionales la información en él publicada. Durante el periodo 1976-1979, la información publicada en el Anuario de la OIT coincide con la que Maluquer y Llonch (2005) atribuyen al Ministerio de Trabajo, con la única excepción de las jornadas no trabajadas en el año 1976 (13.593.100 según los autores citados y 12.593 .100 según el Anuario; esta última cifra es la que reproducen Martínez-Alier y Roca (1988) pero sin hacer referencia a la fuente de información empleada). De igual forma, estos datos coinciden con los utilizados por Alonso (1991) para los años 1977 a 1979 cuya fuente es "Ministerio de Economía y Hacienda, La negociación colectiva en 1985, a partir de datos del Ministerio de Trabajo". 
Para las anualidades comprendidas entre los años 1980 a 1985, la información publicada en el Anuario ha sido comparada con la proporcionada por el Boletín de Estadísticas Laborales del Ministerio de Trabajo. Durante este periodo no se incluyen datos sobre las jornadas no trabajadas en Cataluña, y no se incluye ningún dato sobre Cataluña entre los años 1983 a 1985. Estas omisiones se han tenido en cuenta a la hora de confeccionar los índices de conflictividad, excluyendo los asalariados de Cataluña cuando así procede. Así mismo, durante el intervalo 1986-89 no se dispone de información sobre el País Vasco.

\section{LA EVOLUCIÓN DE LA ACTIVIDAD HUELGUísTICA DESDE EL FIN DE LA DICTADURA}

Las series de huelgas, participantes y jornadas no trabajadas (Anexo 1) se pueden dividir a grandes rasgos en cuatro etapas en función de la intensidad de la actividad huelguística. Cambios de intensidad que se reflejan en la "forma de las huelgas" (Shorter y Tilly 1971).

La división que aquí se propone es - como casi todas las divisiones- en cierta medida artificial, pero para nada arbitraria al tomar como puntos de corte los principales puntos de inflexión registrados en la intensidad de la actividad huelguística.

La primera etapa comprende el periodo de transición al régimen democrático en el que se legalizan las huelgas tras casi cuatro décadas de represión y se caracteriza por registrar un grado de movilización desconocido desde entonces. La segunda etapa (1980-86) se identifica en el terreno de las relaciones laborales por tratarse de un periodo de concertación social y de despolitización del conflicto industrial que se circunscribe al ámbito de la empresa en pleno proceso de reconversión industrial. La tercera etapa se prolonga desde finales de los ochenta hasta mediados los noventa, periodo que se caracteriza por la repolitización del conflicto que se refleja en la convocatoria de tres huelgas generales de ámbito nacional. Por último, la cuarta etapa, desde la segunda mitad de los noventa hasta el año 2008, es la del declive y posterior estabilización de los niveles de conflictividad en un punto de aparente equilibrio; se caracteriza por un crecimiento económico continuado y el resurgimiento de la concertación social. 


\section{Gráfico 1.}

Intensidad de la actividad huelguística.

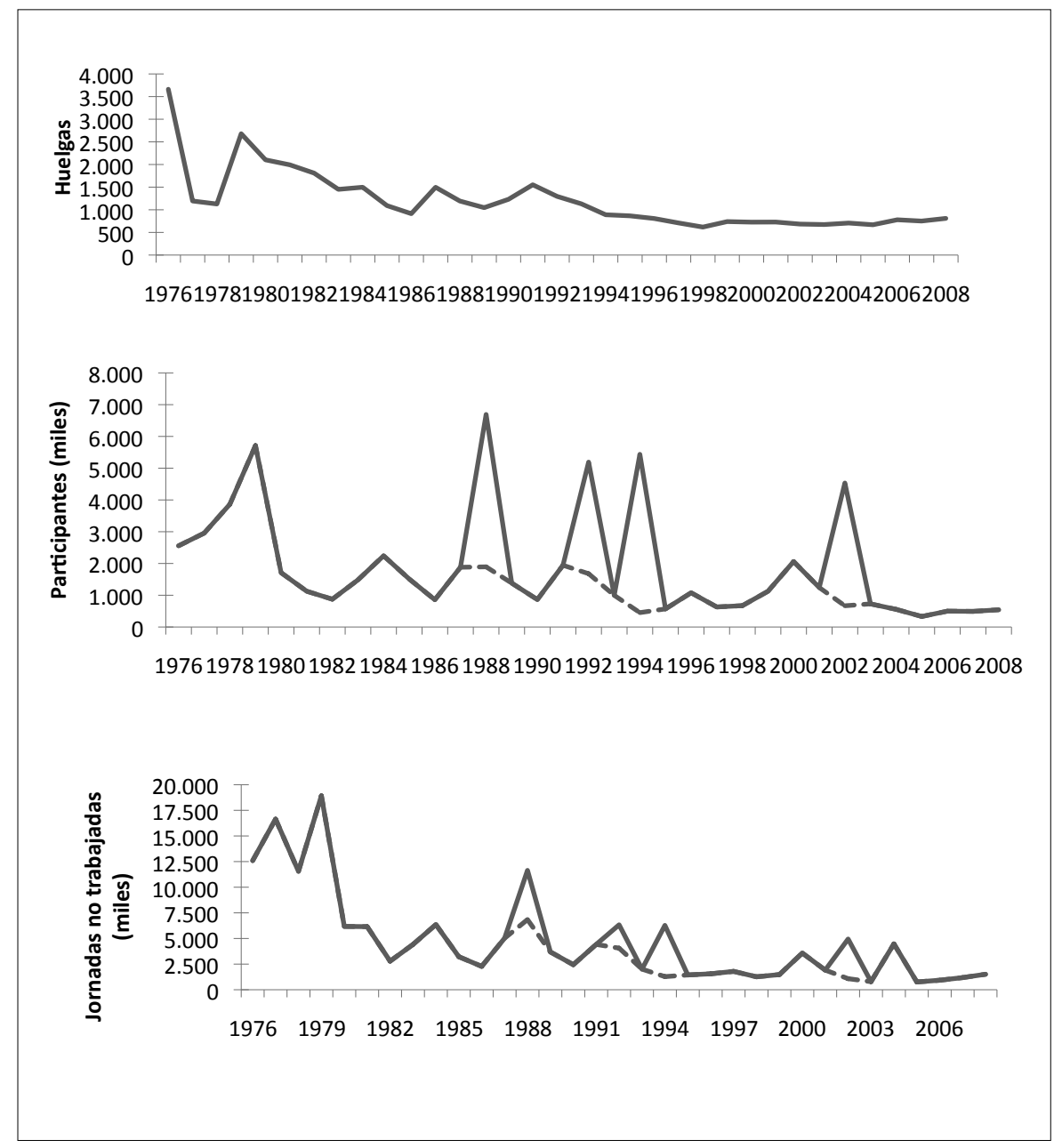

Nota: La línea punteada no incluye las cuatro huelgas generales de ámbito nacional acontecidas durante el periodo de análisis: 14 de diciembre 1988, 28 de mayo de 1992, 27 de enero de 1994 y 20 junio de 2002. Fuente: Anuario de Estadísticas del Trabajo (OIT) y Estadística de Huelgas y Cierres Patronales (MTIN). 


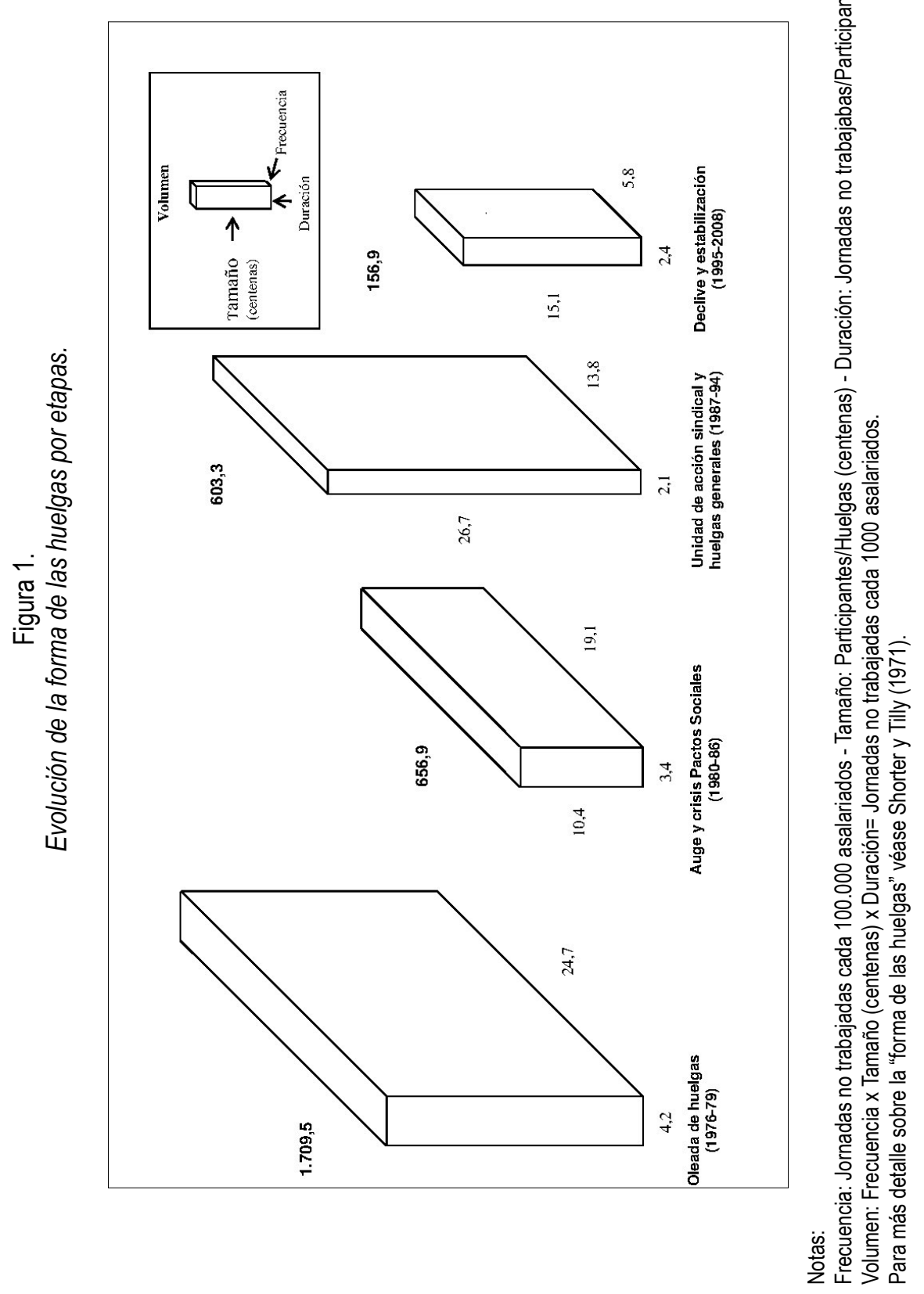

RIS, VOL. 70. No 3, SEPTIEMBRE-DICIEMBRE, 561-585, 2012. ISSN: 0034-9712. DOI: 10.3989/ris.2011.02.25 


\section{A. Oleada de huelgas (1976-1979)}

Tras la muerte de Franco, en el año 1976 se registra un aumento espectacular del número de huelguistas y de las jornadas no trabajadas. Este auge de la actividad huelguística no supone un hecho distintivo del caso español, dado que en prácticamente todos los procesos de redemocratización incluyen un brusco incremento de activación del movimiento obrero a través de huelgas y manifestaciones (Valenzuela 1989). De igual forma, Shorter y Tilly (1974) señalan que las "crisis políticas" constituyen un tipo de condición previa para que se produzca una oleada de huelgas, aunque no sea por sí misma suficiente. Por tanto, la peculiaridad del caso español viene marcada por la coincidencia en un mismo periodo histórico del final de un ciclo largo en la actividad económica, momento en el que las mayores agitaciones tienden a estallar (Screpanti 1987), y un cambio de régimen político, lo que hizo que la explosión huelguística fuese de una magnitud extraordinaria.

Así, durante esta etapa las huelgas se caracterizan, además de por la extraordinaria frecuencia, por su gran tamaño; lo que les confiere un gran componente políticoexpresivo y reflejan el incremento de la capacidad organizativa de los sindicatos para atraer un mayor número de trabajadores, ya sea de un centro aislado o de varios. Por último, su prolongación durante varios años hace que se cumplan los tres criterios con los que Forcheimer (1948) define las "oleadas de huelgas": agudeza, extensión entendido a nivel nacional como tamaño y duración — prolongación durante varios años. Esta combinación de huelgas frecuentes y de gran magnitud se traduce en un volumen de huelgas de 1,7 jornadas no trabajadas por asalariado y año.

El alto grado de movilización se aprecia tanto en el número de huelguistas (entre 2,5 y 5,7 millones anuales) como en el volumen de jornadas no trabajadas (entre 11,5 y 18,9 millones). En perspectiva comparada, un aspecto destacable es que esta oleada de huelgas se produce en nuestro país con retraso respecto a la mayor parte de las democracias europeas, que experimentaron la última gran oleada de huelgas a finales de los sesenta y principios de los setenta (Crouch y Pizzorno 1978a; 1978b); hecho atribuible al distinto contexto político en el que se encontraba España en dicho periodo. En 1977 se produce la ruptura del modelo de relaciones laborales, fuertemente intervenido, vigente durante la dictadura. El cambio del marco institucional se inició con el Real Decreto-Ley 17/1977, de 4 de marzo, sobre Relaciones de Trabajo, que reconoce el derecho de huelga ${ }^{1}$, y apenas un mes más tarde los sindicatos se legalizan por la Ley 19/1977, de 1 de abril, sobre regulación del derecho de asociación sindical.

En ese mismo año se evidencian dos circunstancias con una importante repercusión en los años posteriores: por un lado, la confrontación de las dos principales centrales sindicales, Comisiones Obreras (CCOO) y Unión General de Trabajadores (UGT), y, por el

\footnotetext{
${ }^{1}$ Para mayor detalle respecto a la regulación del derecho de huelga en España, véase García Murcia y Castro Argüelles (2011).
} 
otro, la apertura de la política de pactos. Así, en marzo UGT decide no seguir participando en la Coordinadora de Organizaciones Sindicales (COS), suscrita inicialmente a mediados de 1976 por UGT, CCOO y la Unión Sindical Obrera (USO), con la que se trataba de instaurar la unidad de acción sindical. Respecto a la política de pactos, con los Pactos de la Moncloa de octubre de 1977 se inició una etapa de subordinación explicita de la negociación colectiva a la política macroeconómica y, en especial, a la reducción de la inflación (Roca 1991). Aunque los sindicatos no participaron en la firma apoyaron decisivamente mediante el voto afirmativo de sus dirigentes en el Parlamento; lo que supuso el inicio del declive de los movimientos autónomo-asamblearios que habían sido protagonistas en la etapa anterior, aunque no ocasionó la brusca desaparición de los mismos (Quintana 2002).

\section{B. Auge y crisis de los pactos sociales (1980-1986)}

Tras la explosión de conflictividad de finales de los setenta, con el cambio de década se abre una nueva etapa en la que desciende marcadamente el volumen de actividad huelguística. En esta etapa tuvo lugar un proceso de concertación nacional -iniciado en la etapa anterior- que implicó, en distintos momentos, al gobierno, a los sindicatos y a la patronal, y que puede verse como un intento de intercambio bipartito o tripartito, en el que los sindicatos aceptaron una restricción salarial a cambio de concesiones por parte del gobierno o de los empresarios en materia de legislación laboral y creación de empleo (Martínez Lucio 2002).

En clave económica, en 1979 tuvo lugar la segunda crisis del petróleo, que tuvo consecuencias mucho más negativas sobre la situación económica. Desde el año 1979 y hasta 1985 la economía española experimentó una recesión profunda que tenía causas más diversas y complejas que la subida del precio del petróleo. La crisis tenía un carácter estructural (Marín, Molinero e Ysás 2001). La reestructuración de la industria básica, sobre todo en el sector público empresarial, generó conflictos de gran envergadura lo que hizo que los niveles de conflictividad se mantuviesen en niveles elevados en términos comparados con el resto de países europeos.

Por tanto, durante esta segunda etapa "el conflicto se presenta en dos niveles": a nivel institucional, entra en una etapa de concertación corporatista subordinada, expresada en una política de sucesivos pactos sociales; de forma paralela, el conflicto abierto se desplaza hacia los centros concretos de actividad (Alonso 1991). Este desplazamiento del conflicto a los centros de producción se refleja claramente en el cambio experimentado en la forma de las huelgas: su tamaño se reduce a la mitad respecto a la etapa anterior.

A nivel institucional, como continuación de la política iniciada en 1979 con el Acuerdo Básico Interconfederal, en enero de 1980, Confederación Española de Organismos Empresariales (CEOE) y UGT firman el Acuerdo Marco Interconfederal (AMI) de carácter bianual que regularía la negociación colectiva durante 1980 y 1981. Posteriormente se adhiere USO. Este acuerdo supuso la continuación pero por un nuevo cauce -el 
gobierno ya no impuso sino que se limitó a sugerir la pauta salarial de acuerdo a la inflación prevista- de la política de rentas. En junio de 1981 se firma el primer pacto de carácter tripartito, con la participación del Gobierno, la principal asociación empresarial (CEOE) y las dos principales confederaciones sindicales (UGT y CCOO), con el nombre de Acuerdo Nacional sobre Empleo (ANE), también conocido como el "pacto del miedo" al firmarse bajo el trauma del golpe de Estado del 23 de Febrero. En 1983 CEOE, UGT y CCOO firman el Acuerdo Interconfederal (Al). Por último, a finales de 1984 se firma un nuevo acuerdo tripartito, el Acuerdo Económico y Social (AES), al que se suman, además del Gobierno, la CEOE, Confederación Española de la Pequeña y Mediana Empresa (CEPYME) y UGT con vigencia durante 1985 y 1986.

En el ámbito de las relaciones laborales, en 1982 acontecen las terceras elecciones sindicales que reforzaron la tendencia al bisindicalismo y otorgaron la hegemonía por primera vez a UGT $(36,7 \%$ de los delegados) frente a CCOO $(33,4 \%)$. Lo que da a entender que los trabajadores recompensaron el rumbo moderado de UGT, las negociaciones de convenio a nivel central, la moderación salarial, y los pactos sociales que se firmaron con el gobierno y con los empresarios (Köhler 1995).

La llegada del Partido Socialista Obrero Español (PSOE) al gobierno en ese mismo año plantea un "difícil dilema" al movimiento sindical, sobre todo a UGT: intentar obtener sus objetivos en el ámbito político a través de la colaboración con su partido de referencia, o bien tratar de alcanzarlos en el mercado de trabajo - donde la huelga es el principal medio de presión- cooperando con $\mathrm{CCOO}$, para lo que debería romper sus lazos con el partido (Astudillo 2001; 2004). UGT optó por colaborar con el Gobierno (no en vano, algunos líderes de UGT habían sido elegidos como diputados en las listas del PSOE) y subordinar los intereses del sindicato a los del partido. Entonces, las estrategias de las dos principales confederaciones sindicales tomaron sentidos diametralmente opuestos: CC.OO - por clara divergencia ideológica - adoptó una posición crítica rechazando tomar parte en cualquier acuerdo tripartito. Por tanto, desde la óptica del "intercambio político" (Pizzorno 1978), UGT habría optado por mantener una estrecha relación con el PSOE al considerar esta la mejor estrategia para la defensa de los intereses de los trabajadores como clase y para reforzarse como organización: moderación en el corto plazo en el mercado de trabajo a cambio de mejores expectativas en el medio y largo plazo a través de los recursos políticos (fiscalidad, gasto social, etc.).

En el año 1985 se detectan los primeros síntomas de recuperación económica y se desencadenan una serie de acontecimientos que dejan clara constancia de que la política de pactos está llegando a su fin. El detonante inmediato fue la promulgación por parte del Gobierno de la Ley 26/1985, de 31 de julio, conocida en su momento como de Reforma de Pensiones. La reacción de los sindicatos ante la inminente aprobación de la ley no se hizo esperar, a primeros de junio la UGT convoca su primera manifestación contra el Gobierno socialista a la que se une CCOO, y el día 20 tuvo lugar la primera huelga general de ámbito nacional de la democracia española convocada por los principales sindicatos, a excepción de UGT, de resultado poco espectacular (Alonso 1991). La ley no se retiró. 
Si bien en el ámbito institucional esta etapa se caracteriza por el auge y declive de los pactos sociales, paralelamente se produce un desplazamiento de la actividad huelguística hacia los centros productivos debido al comienzo en serio de la reconversión industrial, con la consiguiente pérdida de puestos de trabajo como consecuencia de la inevitable aplicación de medidas de ajuste duro. A esto se le suma la escasa disposición del Gobierno al diálogo con los sindicatos, que provocaron un rosario de luchas obreras (Marín 2001). Los cierres, los "planes de competitividad" y los "contratos-programa", que supusieron el despido o jubilación anticipada de decenas de miles de trabajadores y que encontraron una ruidosa resistencia sindical, afectaron en sucesivas oleadas hasta bien entrados los años noventa a los sectores de la siderurgia, la minería del carbón, la construcción naval, y a otras actividades como los bienes de equipo y los contratistas de defensa. El año 1984 fue el más conflictivo de esta etapa por la concurrencia de diversos problemas de gran calado en diversas industrias en reestructuración.

\section{Unidad de acción sindical y huelgas generales (1987-1994)}

El inicio de esta tercera etapa coincide con el cambio en la coyuntura económica (expansión entre 1987 y 1991) y se caracteriza en el ámbito institucional por ser un período de confrontación entre los sindicatos y el Gobierno. Lo que lleva a Marín (2001) a definir este periodo de la historia política de España como "el enfrentamiento con los sindicatos". Así, desde 1986 los sindicatos reclamaron al Gobierno una serie de medidas que compensaran la "deuda social" por los importantes sacrificios que había supuesto para los trabajadores la crisis; mientras que el Gobierno mantenía una política económica cuyo objetivo principal era la lucha contra la inflación y que, por tanto, suponía la negativa a las demandas sindicales. Todo lo cual desembocó en la convocatoria de hasta tres huelgas generales de ámbito nacional en un periodo de seis años, que aglutinaron algo más de la mitad $(54,5 \%)$ del total de participantes en huelgas durante esta etapa. Manteniendo de esta forma el promedio anual de participantes por encima de los tres millones y aumentando considerablemente el tamaño medio de las huelgas respecto a la etapa anterior. No obstante, el volumen de huelgas se reduce debido a que tanto la frecuencia como la duración se reducen.

La forma típica de las huelgas en esta etapa, alta participación en confrontaciones breves, viene determinada por las huelgas generales de ámbito nacional y son reflejo de un sistema de relaciones laborales que, lejos de ser autónomo o aislado, está en estrecha relación con el sistema político.

Tras la finalización de la vigencia del AES, las conversaciones entre Gobierno y sindicatos para establecer un acuerdo para 1987 fracasan y la concertación social se hace insostenible. Para los sindicatos se evidencia un desgaste en su propia legitimación al haber asumido los costes de la autolimitación de los salarios sin conseguir las contrapartidas de coberturas sociales o creación de empleo (Morán 1996). De este modo, durante el periodo de pactos sociales de los ochenta, los salarios reales de los trabajadores disminuyeron en cada una de las anualidades; en contraste, en esta nueva etapa los 
salarios reales aumentan de forma continuada desde 1987 hasta 1993 (Gráfico 2). Sin embargo, a pesar de la moderación salarial practicada por los sindicatos, durante el periodo 1983-1986 se continuaba destruyendo empleo mientras que la economía crecía a una tasa anual en torno al dos por ciento (gráfico 3).

Por otra parte, Gobierno y empresarios perdieron parcialmente su interés en realizar acuerdos, debido a que la creciente recuperación económica hacía menos crucial la variable salarial que en los años anteriores (Alonso y Blanco 1999).

En este contexto los sindicatos mayoritarios (UGT y CC.OO) rompen relaciones con sus respectivos partidos de referencia: PSOE y PCE. Este distanciamiento en las relaciones con sus partidos posibilita la cooperación entre los sindicatos tratando de monopolizar la representación de los trabajadores en busca de una actuación más eficaz en el mercado de trabajo, así como una mayor capacidad de presión externa en el ámbito político. De esta forma, CCOO y UGT entran en una dinámica de unidad de acción con la que exigen un giro en la política económica y el cobro de lo que se vino a llamar la "deuda social".

El cambio de clima en las relaciones laborales y la ruptura de la dinámica de concertación social desarrollada hasta 1986 se escenifica con toda su crudeza en la convocatoria de huelga general (de ámbito nacional) el 14 de diciembre de 1988 -la segunda de la democracia y la primera convocada conjuntamente por CCOO y UGT-con ocasión del Plan de Empleo Juvenil; si bien, en realidad, la huelga es una manifestación del rechazo frontal a la política económica del Gobierno socialista en su conjunto.

Tras la huelga general se inicia un "giro estratégico" en los sindicatos mayoritarios, basado fundamentalmente en el abandono de la tradicional actitud reactiva y de protesta, y el cambio hacia una intervención crecientemente proactiva y propositiva, orientada a la mejora de la cantidad y calidad del empleo (Beneyto 2008). De este modo, CCOO y UGT elaboran en 1989 una política unitaria denominada Propuesta Sindical Prioritaria.

El 28 de mayo de 1992 acontece la segunda huelga general de esta etapa ante el "decretazo" de recorte de prestaciones por desempleo, aunque esta vez la huelga general no consigue la retirada del decreto. El 27 de enero de 1994 tuvo lugar la tercera huelga general ante la reforma del mercado de trabajo anunciada por el Gobierno. La convocatoria fue seguida por casi cinco millones de asalariados y puso de manifiesto una vez más la gran capacidad de movilización de los sindicatos, así como su limitado impacto político al no evitar la aprobación de la reforma por el Parlamento.

Además de las huelgas generales, durante esta etapa, como continuación de la anterior, los procesos de reducción de plantillas en los sectores siderúrgico, naval, minero y de bienes de equipo desencadenan los conflictos sociolaborales más característicos del periodo (Alonso y Blanco 1999). Sucediéndose manifestaciones y agrios conflictos de carácter defensivo ante el desmantelamiento del sector público industrial que, protagonizados principalmente por los núcleos obreros de las grandes empresas, se extienden a regiones enteras cuyo sustento depende en gran medida de esas actividades productivas. 
Esta etapa se cierra con un nuevo "examen" al que se han de someter periódicamente las estrategias sindicales: las elecciones a representantes de los trabajadores (Espina 1999). Si las elecciones generales de 1993 habían puesto de manifiesto que la confrontación entre sindicatos y el Gobierno se tradujo en un importante desgaste electoral para este último, no fue lo suficiente como para no ganar las elecciones. Las elecciones sindicales de 1994-95 supusieron un duro golpe a la estrategia sindical de confrontación con el Gobierno, sobre todo para UGT, que perdió más de 25.000 delegados respecto a las elecciones de 1990, consiguiendo el 34,7 por ciento del total; CCOO obtuvo 10.000 delegados menos que en la convocatoria anterior pero con el 37,8 por ciento del total de votos recuperará la hegemonía sindical perdida en 1982. El mensaje resultante de estas elecciones fue claro: frente a la estrategia de confrontación, impulsada por las cúpulas sindicales, los electores favorecieron a los representantes no alineados -aumentó en términos absolutos y relativos el número de representantes obtenidos por "otros sindicatos" distintos a los mayoritarios-, optando implícitamente por una negociación más próxima a las realidades específicas de la empresa (Espina 1999).

\section{Declive y estabilización (1995-2008)}

La cuarta etapa en la evolución del grado de intensidad de la actividad huelguística en España durante el periodo democrático, la del declive y posterior estabilización del número de huelgas, se inició a mediados de los noventa. De este modo, el año 1995 es el primero del régimen democrático en el que el número de jornadas no trabajadas debido a huelgas no supera los dos millones. Respecto al número de conflictos, el descenso comienza en 1992 para estabilizarse desde la segunda mitad de los noventa en torno a una media de 700 huelgas al año cuando previamente sobrepasaba ampliamente las mil. De igual modo, disminuye el tamaño medio de las huelgas. Lo que denota una separación del conflicto político del contractual. Como resultado el volumen de huelgas se reduce a la cuarta parte respecto a la etapa previa.

No obstante, se aprecian ciertos repuntes, todos ellos debidos a conflictos localizados y no a una conflictividad generalizada. El de mayor magnitud como consecuencia de la huelga general de 20 de junio de 2002, ante un nuevo "decretazo" de reforma del despido y del sistema de protección por desempleo.

Esta última etapa se afronta con importantes cambios organizativos y estratégicos en los sindicatos más representativos de ámbito nacional. Tras la crisis interna y la renovación de la ejecutiva de UGT en los años 1994 y 1995, en el año 1996 CCOO celebró su VI Congreso, en el que el sector antagonista fue separado de todas las tareas ejecutivas y quedó en abierta minoría formando el autodenominado "sector crítico". Por tanto, en ambos casos los líderes carismáticos, Nicolás Redondo y Marcelino Camacho, abandonan definitivamente sus puestos en la dirección de los sindicatos.

Un contexto de alto desempleo y elevada temporalidad, de cambio profundo en la estructura ocupacional y segmentación e individualización de las relaciones laborales 


\section{Gráfico 2.}

Evolución de los aumentos salariales pactados en los convenios colectivos, de las variaciones del Índice de Precios al Consumo y de los salarios reales.

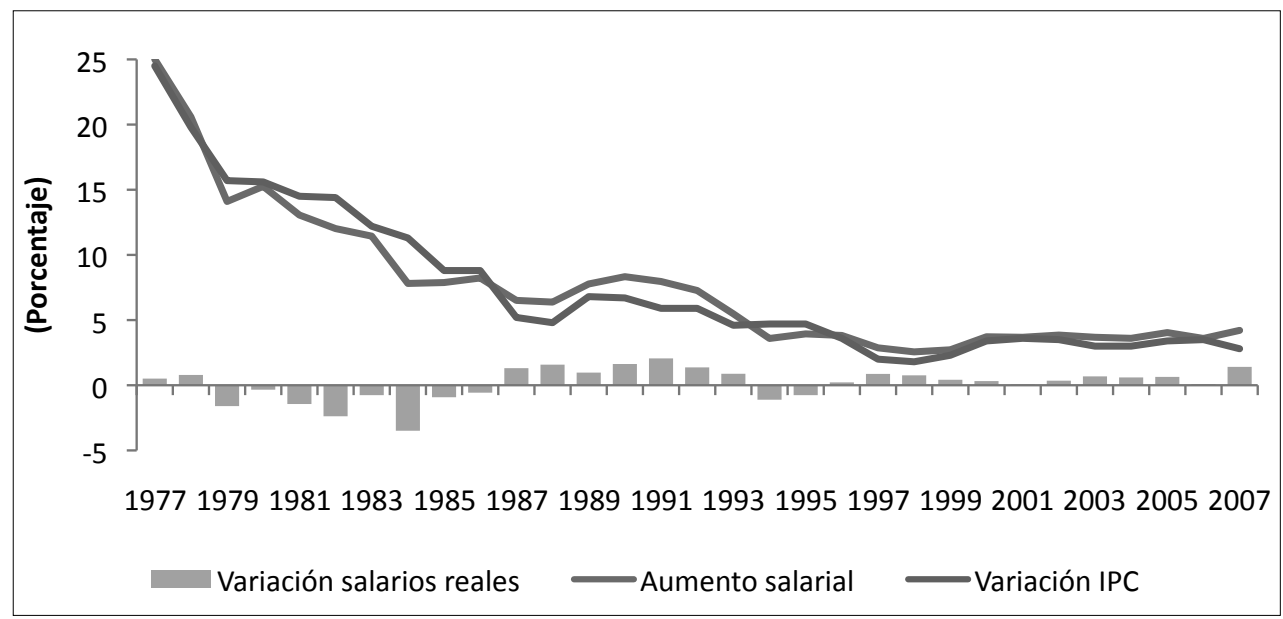

Fuente: Elaboración propia a partir del Boletín de Estadísticas Laborares, MTIN y IPC, INE.

\section{Gráfico 3.}

\section{Evolución de las variaciones anuales en el volumen}

total de empleo y Producto Interior Bruto.

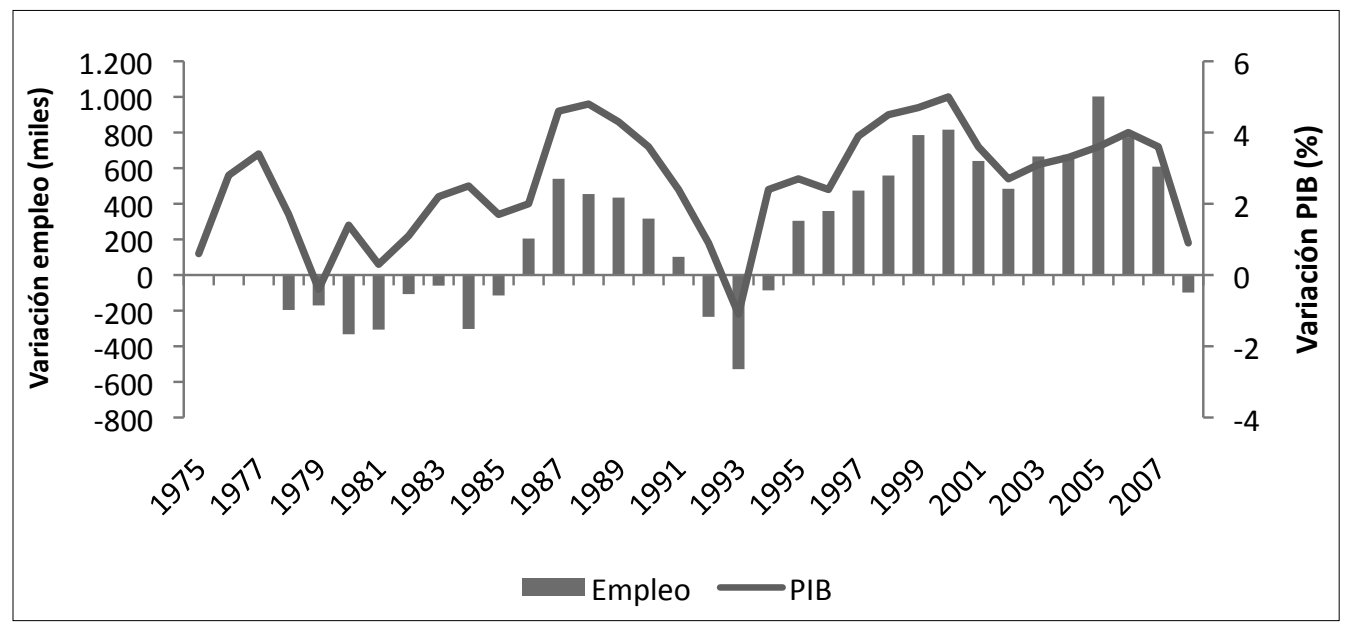

Fuente: Elaboración propia a partir de Encuesta Población Activa (INE) y Contabilidad Nacional (INE): Ios datos del PIB de 2006 y 2007 son provisionales y los de 2008 un avance. 
hace que los sindicatos vuelvan a examinar su estrategia. Como resultado del "proceso de aprendizaje institucional" de la etapa anterior, los líderes sindicales llegaron a la conclusión de que la estrategia de confrontación tuvo resultados contraproducentes para sus intereses, al erosionar tanto su influencia política —no pudieron evitar las reformas orientadas a liberalizar el mercado de trabajo- como el apoyo de su electorado malos resultados en las elecciones sindicales de 1994-95-, amenazando su propia supervivencia (Royo 2006). De esta forma, se produce una reorientación estratégica en los sindicatos más representativos a nivel nacional con el fin de retomar la iniciativa y la influencia a nivel político, acelerada por los cambios internos llevados a cabo. A lo que se suma, por un lado, la incapacidad de los empresarios para controlar los salarios, y, por el otro, la incapacidad del Gobierno en reducir la inflación, con el fin de cumplir con los criterios de convergencia establecidos en el proceso de creación de la Unión Económica y Monetaria, en ausencia de un marco de negociación centralizado (Pérez 2000).

Como resultado, se retoma la política de concertación, paradójicamente, de forma más intensa tras el cambio de Gobierno en las elecciones generales de 1996 ganadas por el Partido Popular (PP). Esta forma de operar del Gobierno de Aznar, no aplicando una agenda neoliberal ortodoxa, negociando las reformas - al menos durante la primera legislatura - lleva a Hamann (2005) a presentar al Gobierno del PP como una "tercera vía conservadora". Por otro lado, la estrategia de establecer mesas de negociación independientes - de forma que el desacuerdo en una no afecte al proceso de negociación en el resto-y de iniciar las negociaciones por las materias en las que el consenso entre los agentes sociales era elevado, facilitó el éxito del proceso negociador. Con la vuelta al gobierno del PSOE en 2004, el diálogo social tomó un nuevo impulso tras el retroceso sufrido en la segunda legislatura del PP — esta vez con mayoría absoluta-, con huelga general de ámbito nacional incluida el 20 de Junio de 2002, que supuso un paréntesis en la política de concertación, y, como consecuencia, ante un cambio de posición del Gobierno, no favorable a los intereses de los trabajadores, el intercambio se volvió negativo de manera puntual.

En esta etapa la relación en el proceso de concertación centralizada y la disminución de la actividad huelguística es más clara que la acontecida en la etapa de los grandes pactos sociales, en la medida en que en los años ochenta el efecto de los acuerdos centralizados fue contrarrestado ampliamente por los conflictos de gran calado desencadenados por la reestructuración del sector público empresarial. Por tanto, desde la óptica del "intercambio político" los sindicatos desde la segunda mitad de los noventa han considerado ventajoso (menos costoso) desplazar la lucha por la distribución desde el mercado de trabajo al ámbito político, lo que ha significado una reducción acusada de la actividad huelguística. Además, desde mediados los noventa también se ha desarrollado un intenso proceso de concertación a nivel regional que, partiendo de los pactos territoriales por el empleo, se ha extendido a otros ámbitos como inversiones en infraestructuras y mejora de los servicios sociales. Implicando, de este modo, cada vez más a los agentes sociales en el diseño y la gestión de políticas públicas alejándolos progresivamente de la confrontación en las relaciones laborales. 
En el ámbito económico, hay que destacar dos aspectos del proceso de convergencia nominal y final integración de España en la Unión Económica y Monetaria (UEM) que parecen haber tenido efectos encontrados, aunque no simétricos, en la actividad huelguística. Por un lado, la reducción sustancial de la tasa de inflación se asocia a una reducción permanente de las huelgas derivadas del proceso de negociación colectiva; y por el otro, la reducción del déficit y de la deuda pública se relaciona con la convocatoria esporádica de huelgas como consecuencia de la privatización de las grandes empresas públicas y la congelación de los salarios de los funcionarios (la última en el año 2000).

En el gráfico 4 se aprecia cómo el incremento de los precios y el número de huelgas derivadas de la negociación colectiva muestran una evolución acompasada. Así, en la primera mitad de los noventa las huelgas derivadas de la negociación colectiva disminuyen, a la par que el incremento de los precios se reduce. A finales de los noventa se registra el valor mínimo en ambas series. En contraste, con el cambio de década se acelera el incremento de los precios, aumenta de igual forma el número de huelgas derivadas del proceso de negociación colectiva. Por último, en lo que va de década ambas magnitudes se han estabilizado. Este último hecho se puede relacionar con la firma por parte de sindicatos y patronal de sucesivos Acuerdos Interconfederales sobre Negociación Colectiva desde el año 2002 hasta 2008.

Gráfico 4.

Evolución del número de huelgas derivadas de la negociación

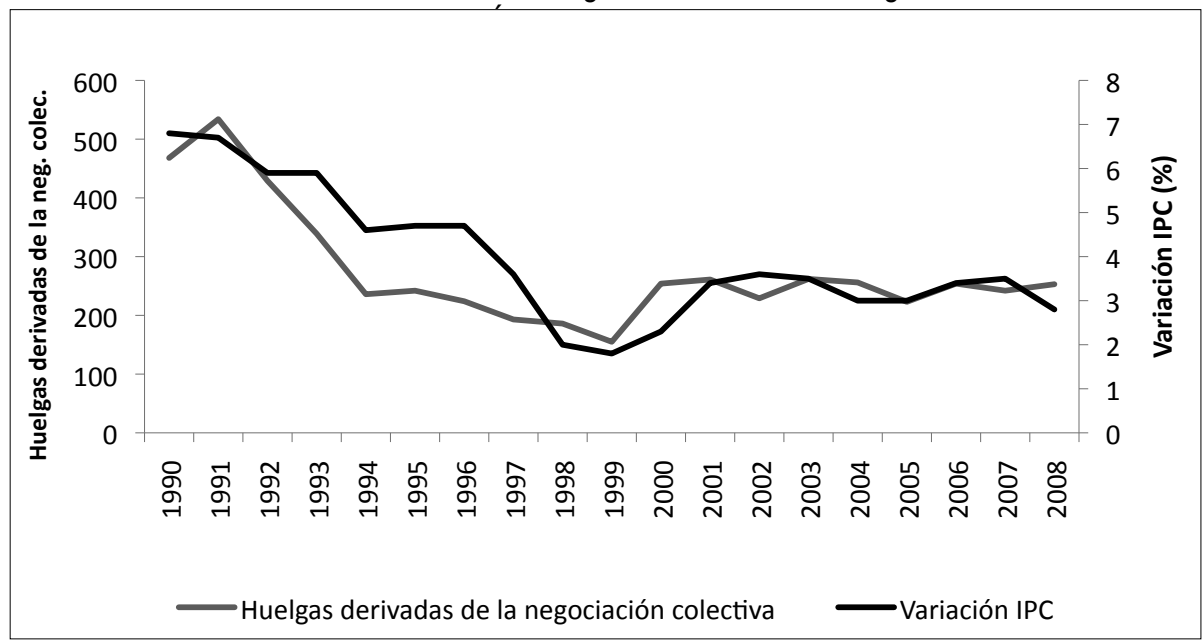

*La serie del IPC se ha introducido con un año de retardo, en el sentido planteado por Cramton y Tracy (2003) de que las huelgas pueden ser más frecuentes cuando en el periodo previo se ha producido un comportamiento descompensado de la tasa de inflación.

Fuente: Elaboración propia a partir de Estadistica de Huelgas y Cierres Patronales (MTIN) y Índice de Precios de Consumo (INE). 
De igual modo, cabe destacar como otra de las causas del descenso acusado de la actividad huelguística en esta etapa la puesta en marcha, tanto a nivel nacional (Servicio Interconfederal de Mediación y Arbitraje) como regional, de procedimientos de solución extrajudicial de conflictos colectivos de trabajo mediante acuerdos interprofesionales sobre materias concretas. Con el paso de los años, estos procedimientos de mediación $y$, en su caso, arbitraje, se han convertido en verdaderos instrumentos dinamizadores de las relaciones laborales al fomentar la búsqueda de soluciones consensuadas sin necesidad de recurrir a actuaciones de mayor contundencia. Además, prevén una mediación previa a la convocatoria de huelgas, lo que supone una reducción directa de la actividad huelguística en caso de acuerdo, sin perjuicio del descenso indirecto derivado del mejor entendimiento de las partes. Estos mecanismos han supuesto el cierre del círculo de la institucionalización del conflicto de trabajo.

\section{Conclusiones}

En el análisis realizado sobre evolución de la actividad huelguística durante el periodo democrático en España queda patente una reducción muy drástica de la misma. Así, el volumen de huelgas durante la etapa más reciente (1995-2008) tan solo supone la décima parte del registrado a finales de los setenta.

En cuanto a la evolución de la configuración o forma de las huelgas, la reducción de su tamaño, respecto al principio del periodo democrático, indica una separación del conflicto político - que se desplaza al ámbito del diálogo social- del contractual o de mercado. La reducción de la duración de las huelgas muestra que han pasado de ser una "demostración de fuerza" entre trabajadores y empleadores al inicio del periodo democrático (4,2 jornadas no trabajadas por asalariado y año) a una "forma de presión" durante la negociación colectiva y, ocasionalmente, de "demostración de fuerza" en el ámbito político cuando se rompe la dinámica del intercambio. La reducción de la frecuencia de las huelgas refleja una estrategia de "intercambio político" en la cual los sindicatos "renuncian a utilizar plenamente su poder de negociación sobre reivindicaciones inmediatas (esencialmente salariales), a cambio de satisfacer sus reivindicaciones estructurales a más largo plazo" (Rehfeldt 1990:7-8). Como en toda relación de intercambio entran en consideración los beneficios a corto y a largo plazo. De esta forma, los trabajadores renuncian a beneficios a corto plazo, a través de la moderación de sus reivindicaciones, con el fin de otorgar un mayor poder a sus representantes (Ios sindicatos), esto es, capacidad para obtener beneficios o compensaciones del Estado y/o de los empleadores en el futuro a través de la concertación social a cambio del consenso/orden social que ofrecen. Así, la distribución de la renta no se circunscribe de modo exclusivo al mercado, donde la huelga es el principal mecanismo de presión, sino que se traslada en gran parte al ámbito político. 
En definitiva, la hipótesis "política" sobre las huelgas parece más adecuada para explicar el caso español durante el régimen democrático. Así, los sucesivos acuerdos de concertación social acontecidos tanto a nivel nacional como regional desde mediados de los noventa se pueden interpretar, desde la óptica del "intercambio político", como un cambio en la localización del conflicto por la distribución de la renta nacional que se desplaza del mercado - donde las huelgas son el principal mecanismo de presión-a la esfera política, donde operan mecanismos redistributivos a medio y largo plazo como la política social o el sistema fiscal (Cameron 1984; Korpi y Shalev 1979; Hibbs 1978; Pizzorno 1978). Disminuyendo, de este modo, la actividad huelguística en el medio plazo. Sin embargo, lo anterior no implica una evolución lineal de las huelgas en la medida en que se pueden dar discrepancias en el intercambio y las partes se pueden desvincular del mismo y optar por una estrategia de confrontación, como quedó patente en la etapa de finales de los ochenta y primera mitad de los noventa.

No obstante, que las huelgas en España se aproximen más a una lógica de acción política no implica necesariamente que la actividad huelguística se desvincule totalmente de las condiciones económicas. Así, una variable económica como la inflación muestra una influencia relevante en la concurrencia de huelgas durante la negociación colectiva a lo largo del periodo más reciente. La reducción y posterior estabilización del incremento de los precios ha influido, asimismo, en la reducción de la concurrencia de huelgas durante el proceso de negociación colectiva.

\section{REFERENCIAS BibLIOGRÁfICAS}

Alonso, L. E. 1991. "Conflicto laboral y cambio social. Una aproximación al caso español”. Pp. 403-26 en Las relaciones laborales en España, dirigido por F. Miguélez y C. Prieto. Madrid: Siglo XXI.

Alonso, L. E. y J. Blanco. 1999. "La transformación de las bases sociales del conflicto laboral". Pp. 347-74 en Las relaciones de empleo en España, dirigido por F. Miguélez y C. Prieto. Madrid: Siglo XXI.

Ashenfelter, O. y G. Johnson. 1969. "Bargaining theory, trade unions, and industrial strike activity." American Economic Review 59:35-49.

Astudillo Ruiz, J. 2004. "La trampa del partidismo de la UGT: de la relación solidaria con el PSOE a la unidad de acción sindical con CC.0O". Revista Española de Ciencia Política 11:73-101.

Astudillo Ruiz, J. 2001. "Without unions, but socialist: The Spanish Socialist Party and its divorce from its union confederation (1982-96)." Politics \& Society 29:273-296.

Bean, R. 1985. Comparative Industrial Relations. An Introduction to Cross-national Perspectives. Londres: Croom Helm.

Beneyto, P. J. 2008. "El sindicalismo español en perspectiva europea: de la anomalía a la convergencia." Cuaderno de Relaciones Laborales 26:57-88. 
Bordogna, L. 2010. "Strikes in Europe: still a decade of decline or the eve of a new upsurge?." Indian Journal of Industrial Relations 45:646-57.

Cameron, D. R. [1984] 1991. "Democracia social, corporatismo, inactividad laboral y representación de intereses económicos en la sociedad capitalista avanzada". Pp. 207-51 en Orden y Conflicto en el Capitalismo Contemporáneo, compilado por J. Goldthorpe. Madrid: Ministerio de Trabajo y Seguridad Social.

Cramton, P. y J. Tracy. 2003. "Unions, bargaining and strikes". Pp. 86-117 en International Handbook of Trade Unions, editado por J. T. Addison y C. Schnabel. Cheltenham, UK: Edward Elgar.

Crouch, C. y A. Pizzorno. [1978a] 1989. El resurgimiento del conflicto de clases en Europa Occidental a partir de 1968. I Estudios por países. Madrid: Ministerio de Trabajo y Seguridad Social.

Crouch, C. y A. Pizzorno. [1978b] 1991. El resurgimiento del conflicto de clases en Europa Occidental a partir de 1968. II Análisis comparativo. Madrid: Ministerio de Trabajo y Seguridad Social.

Espina, A. 1999. "El Guadiana de la concertación neocorporatista en España: de la huelga general de 1988 a los acuerdos de 1997". Pp. 375-98 en Las relaciones de empleo en España, dirigido por F. Miguélez y coordinado por C. Prieto. Madrid: Siglo XX.

European Industrial Relations Observatory (EIROnline). 2005. Developments in industrial action 20004. Disponible en: http://www.eurofound.europa.eu/eiro/

Forcheimer, K. 1948. "Some international aspect of the strike movements." Bulletin of the Oxford University Institute of Statistics 10:9-31.

Franzosi, R. 1995. The Puzzle of Strikes. Cambridge: Cambridge University Press.

García Murcia, J. y M. ${ }^{a}$ A. Castro Argüelles. 2011. Legislación histórica sobre huelga y conflictos colectivos de trabajo. Navarra: Aranzadi.

Goldthorpe J. H. [1984] 1991. Orden y conflicto en el capitalismo contemporáneo. Madrid: Ministerio de Trabajo y Seguridad Social.

Hamann, K. 2005. "Third Way conservatism? The popular party and labour relations in Spain." International Journal of Iberian Studies 18:67-82.

Hibbs Jr., D. A. 1978. "On the Political Economy of Long-Run Trends in Strike Activity." British Journal of Political Science 8:153-75.

Jiménez-Martín, S. 1999. "Controlling the Endogeneity of Strike Variables in the Estimation of Wage Settlement equations." Journal of Labor Economics 17:587-606.

Jiménez-Martín, S. 2006. "Strike Outcomes and wage settlements in Spain." Labour 20:673-98.

Jiménez-Martín, S., J. M. Labeaga y M. L. Marco Aledo. 1996. "Algunos factores explicativos de la existencia de huelgas durante la negociación colectiva en España." Investigaciones Económicas XX: 217-41. 
Köhler, H.D. 1995. El movimiento sindical en España. Transición democrática. Regionalismo. Modernización económica. Madrid: Fundamentos.

Korpi, W. 1983. The Democratic Class Struggle. Londres: Routledge.

Korpi, W. y M. Shalev. 1979. "Strikes, industrial relations and class conflict in capitalist societies." British Journal of Sociology 30:164-87.

Lange, P. [1984] 1991. "Sindicatos, trabajadores y reglamentación salarial: bases racionales para el acuerdo". Pp. 145-80 en Orden y Conflicto en el Capitalismo Contemporáneo, compilado por J. Goldthorpe. Madrid: Ministerio de Trabajo y Seguridad Social.

Lehmbruch, G. [1984] 1991. «La concertación y la estructura de las redes corporatistas», Pp. 95-122 en Orden y conflicto en le Capitalismo Contemporáneo, compilado por J. Goldthorpe. Madrid. Ministerio de Trabajo y Seguridad Social.

Maluquer de Motes, J. y M. Llonch. 2005. "Trabajo y relaciones laborales". Pp. 1155-246 en Estadísticas históricas de España: siglos XIX-XX, coordinado por A. Carreras y X. Tafunell. Bilbao: Fundación BBVA.

Marco Aledo, M. L y P. Tamborero. 2001. "Las formas de finalización de las huelgas: Análisis de la intervención de terceros en España, 1986-1999". Revista del Ministerio de Trabajo y Asuntos Sociales 31:115-31.

Marco Aledo, M. L, S. Esteve y M. E. Rochina. 2007. "La duración de las huelgas: evidencia empírica para España." Cuadernos Económicos del ICE 73:223-54.

Marco Aledo, M. L. 2000. "El conflicto laboral en España durante el período 1986/1994." Revista del Ministerio de Trabajo y Asuntos Sociales 21:209-33.

Marín, J. M. 2001. "La democracia consolidada, 1982-2000". Pp. 319-480 en Historia política de España (1939-2000), editado por J. M. Marín; C. Molinero y P. Ysás. Madrid: Istmo.

Martínez-Alier, J. y J. Roca Jusmet. 1988. "Economía política del corporatismo en el estado español." Revista Española de Investigaciones Sociológicas 41:25-62.

Ministerio de Trabajo (varios años). Estadística de huelgas y cierres patronales. Madrid.

Molina, O. 2006. "Trade union strategies and change in neo-corporatist concertation: A new century of political exchange?." West European Politics 29:640-64.

Molina, O. y M. Rhodes. 2002. "Corporatism: the past, present, and future of a concept." Annual Review of Political Science 5:305-31.

Morán, A. 1996. "Auge y crisis de los grandes acuerdos sociales de los 80. De la clase obrera al mercado de trabajo." Cuadernos de Relaciones Laborales 9:13-55.

Organización Internacional del Trabajo (varios años). Anuario de estadísticas del trabajo. Génova.

Pérez, S. 2000. "From decentralization to reorganization: Explaining the return to national bargaining in Italy and Spain." Comparative Politics 32:437-58. 
Perry, L. J. y P. J. Wilson. 2008. "Convergence of work stoppages - A global perspective." Journal of World-Systems Research XIII:198-219.

Piazza, J. 2005. "Globalizing quiescence: globalization, union density and strikes in 15 industrialized countries." Economic and Industrial Democracy 26:289-314.

Pizzorno, A. [1978] 1991. "Intercambio político e identidad colectiva en el conflicto laboral". Pp. 381407 en El resurgimiento del conflicto de clases en Europa Occidental a partir de 1968, tomo II, compilado por C. Crouch y A. Pizzorno. Madrid: Ministerio de Trabajo y Seguridad Social.

Quintana, F. (coord.) 2002. Asalto a la fábrica. Barcelona: Alikornio Ediciones.

Regini, M. [1984] 1991. "Las condiciones para el intercambio político: ascenso y decadencia de la concertación en Italia y Gran Bretaña". Pp. 181-206 en Orden y Conflicto en el Capitalismo Contemporáneo, compilado por J. Goldthorpe. Madrid: Ministerio de Trabajo y Seguridad Social.

Royo, S. 2006. "Beyond Confrontation. The resurgence of social bargaining in Spain in the 1990s." Comparative Political Studies 39:969-95.

Schmitter, P. C. 1982. "Reflections on where the theory of corporatism has gone and where the praxis of neo-corporatism may be going". Pp. 259-90 en Patterns of Corporatist Policy-Making, edited by G. Lehmbruch y Ph. E. Schmitter. Londres: Sage.

Screpanti, E. 1987. "Long cycles in strike activity: an empirical investigation." British Journal of Industrial Relations 25:99-124.

Shalev, M. 1989. "Mentiras, mentiras detestables y estadísticas de huelgas: medición de las tendencias del conflicto laboral". Pp. 27-49 en El resurgimiento del conflicto de clases en Europa Occidental a partir de 1968, tomo II, compilado por C. Crouch y A. Pizzorno. Madrid: Ministerio de Trabajo y Seguridad Social.

Shorter, E. y C. Tilly. 1971. "The shape of strikes in France, 1830-1960." Comparative Studies in Society and History 13:60-86.

Shorter, E. y C. Tilly. [1974] 1985. Las huelgas en Francia 1830-1968. Madrid: Ministerio de Trabajo y Seguridad Social.

Valenzuela, S. 1989. "Labor movements in transitions to democracy." Comparative Politics 21:445-72.

Van der Velden, S., H. Dribbusch, D. Lyddon y K. Vandaele. 2007. Strikes Around the World, 1968-2005: Case-studies of 15 countries. Amsterdam: Aksant.

DAVID LUQUE es Diplomado en Relaciones Laborales (2002), licenciado en Ciencia del Trabajo (2004) y Doctor por la Universidad de Oviedo (2010). Entre sus trabajos cabe destacar Las huelgas en España: intensidad, forma y determinantes, Tesis Doctoral Universidad de Oviedo, TESEO."La forma de las huelgas en Europa: 1980-2006", en DD.AA.: La investigación y la enseñanza de la sociología del trabajo: un balance de la situación en España, Alzari (Valencia): Germania, pp. 183-200.

RECIBIDO: $25 / 02 / 2011$

ACEPTADO: $11 / 01 / 2012$

Publicado on-line: 08/05/2012 
Anexo 1.

Número de huelgas, participantes y jornadas no trabajadas, 1976-2008.

\begin{tabular}{|c|c|c|c|}
\hline Año & Huelgas & $\begin{array}{l}\text { Participantes } \\
\text { (miles) }\end{array}$ & $\begin{array}{l}\text { Jornadas no } \\
\text { trabajadas }\end{array}$ \\
\hline 1976 & 3662 & 2556,7 & $12.593,1$ \\
\hline 1977 & 1194 & 2955,6 & $16.641,7$ \\
\hline 1978 & 1128 & 3863,8 & $11.550,9$ \\
\hline 1979 & 2680 & 5713,2 & $18.916,9$ \\
\hline \multirow[t]{2}{*}{1980} & 2103 & 2287,0 & \\
\hline & $(1365)^{*}$ & $(1170,1)^{\star}$ & $6177,5^{*}$ \\
\hline \multirow[t]{2}{*}{1981} & 1993 & 1944,9 & \\
\hline & $(1307)^{*}$ & $(1126,3)^{\star}$ & $5153,8^{*}$ \\
\hline \multirow[t]{2}{*}{1982} & 1.810 & 1058,9 & \\
\hline & $(1225)^{*}$ & $(875,1)^{*}$ & $2787,6^{*}$ \\
\hline $1983^{*}$ & 1451 & 1483,6 & 4416,7 \\
\hline $1984^{*}$ & 1498 & 2242,2 & 6357,8 \\
\hline $1985^{*}$ & 1092 & 1511,2 & 3223,5 \\
\hline $1986 *$ & 914 & 857,9 & 2279,4 \\
\hline $1987^{*}$ & 1497 & 1881,2 & 5025,0 \\
\hline \multirow[t]{2}{*}{$1988^{* *}$} & 1193 & 6692,2 & $11.641,1$ \\
\hline & $(1192)^{1}$ & $(1894,5)^{1}$ & $(6843,4)^{1}$ \\
\hline $1989^{* *}$ & 1047 & 1382,1 & 3685,4 \\
\hline 1990 & 1231 & 864,0 & 2442,8 \\
\hline 1991 & 1552 & 1944,5 & 4421,3 \\
\hline 1992 & 1296 & 5169,6 & 6246,5 \\
\hline \multirow[t]{2}{*}{1994} & 890 & 5427,7 & 6254,7 \\
\hline & $(889)^{3}$ & $(452,8)^{3}$ & $(1279,8)^{3}$ \\
\hline 1995 & 866 & 569,9 & 1442,9 \\
\hline 1996 & 807 & 1078,0 & 1552,9 \\
\hline 1997 & 709 & 631,0 & 1790,1 \\
\hline 1998 & 618 & 671,9 & 1263,5 \\
\hline 1999 & 739 & 1125,1 & 1477,5 \\
\hline 2000 & 727 & 2061,3 & 3577,3 \\
\hline 2001 & 729 & 1242,5 & 1917,0 \\
\hline \multirow[t]{2}{*}{2002} & 684 & 4528,2 & 4938,5 \\
\hline & $(683)^{4}$ & $(668,3)^{4}$ & $(1078,7)^{4}$ \\
\hline 2003 & 674 & 728,5 & 789,0 \\
\hline 2004 & 707 & 555,9 & 4472,2 \\
\hline 2005 & 669 & 331,3 & 758,9 \\
\hline 2006 & 779 & 499,2 & 927,4 \\
\hline 2007 & 751 & 492,2 & 1182,8 \\
\hline 2008 & 810 & 542,5 & 1508,7 \\
\hline
\end{tabular}

Notas: * No incluye Cataluña. ${ }^{*}$ No incluye el País Vasco.

1. No incluye la huelga general de ámbito nacional del 14 de diciembre de 1988.

2. No incluye la huelga general de ámbito nacional del 28 de mayo de 1992.

3. No incluye la huelga general de ámbito nacional del 27 de enero de 1994.

4. No incluye la huelga general de ámbito nacional del 20 de junio de 2002.

Fuente: Anuario de Estadísticas del Trabajo (OIT) y Estadística de Huelgas y Cierres Patronales (MTIN). 